\title{
On Decorative Graphic Design of Zhuang People from the Qin and Han Dynasties to the Five Dynasties*
}

\author{
Jiangming Huang \\ Guangxi Arts University \\ Nanning, China
}

\begin{abstract}
It is the original period for the development of design arts of Zhuang People from the Qin and Han Dynasties to the Five Dynasties. In this period, with the reference of typical patterns of utensils in the Central Plains, decorative graphic designs of the Zhuang People were also created with rich local characteristics and types of decorative patterns were enriched obviously. The application of new technologies promotes the progress of decorative graphic design. The integration of alien culture elements and local culture elements were better applied in design art of decorative pattern.
\end{abstract}

Keywords-Zhuang People; decorative pattern design; from the Qin and Han Dynasties to the Five Dynasties

\section{INTRODUCTION}

It was a period for the formation, development and decline of the slavery of the Zhuang People from the Qin and Han Dynasties to the Five Dynasties, which is the original period for the development of design art of the Zhuang People. The design art of Zhuang ancestors had inherited the characteristics of the Pre-qin Period. In the cultural integration of Central Plains, design arts of Zhuang ancestors showed new characteristics, which has laid a foundation for the national characteristics of design art of the Zhuang People.

Since the First Emperor of the Qin Dynasty unified the south of Five Ridges, he set three counties, including Guilin, Xiangjun and Nanhai, in the south of Five Ridges. Luoyue people, ancestors of the Zhuang People, in the south of Five Ridges began to be under the rule of the feudal dynasty of Central Plains. The Qin Dynasty migrated people from Central Plains to the Five Ridges and made them "live together with Yue people". However, people being migrated there were only a few compared with the number of local people. "Local people didn't obey the prefecture officials appointed by the Qin Dynasty". Therefore, the prefectures and counties established by the Qin Dynasty couldn't prevent the formation and development of the slavery of Yue

*The paper is a general item of humanities and social sciences research of National Ministry of Education in "History of Design Art and Research of Culture of Zhuang People" (item number:11YJA760055) and the staged research results of scientific and research program of Guangxi Education Department in "History of Design of Zhuang People" (GJKY[2009]221/200911MS176). people in the Five Ridges. [2]In this period, the productive relationship of the feudalism has been gradually established and developed in most of prefectures and counties with the great influence of Han culture due to the advantages of flat terrain and convenient transportation. However, most of regions Zhuang people lived far from the rule of prefectures and counties, with inconvenient traffic, still maintained the productive relationship of the primitive tribe and family slave society. For example, in the westernmost of Zhuang regions, ancient Yue people and $\mathrm{Pu}$ people established two slavery states of Juding State and Yelang State. After Emperor Wu of Han Dynasty calmed down the south regions Yue people lived, he set up three counties, including Cangwu, Yulin, Hepu, and 27 prefectures under these counties to further enhance the government in the south of Five Ridges. The slavery states of Yue people and $\mathrm{Pu}$ people were both under the jurisdiction of Zangke County.

In the Wei, Jin, Southern and Northern Dynasties, the immigration of Han people due to war further developed the social culture in regions of Zhuang people. In the Tang Dynasty, governors implemented "Jimi System" in the south of Five Ridges, and carried out the policies of "preserving the tribes", "not abolishing local customs", "reducing the burden of taxation and cost" and "governing local people with local governors". By implementing the Jimi System, the Central Dynasty both governed the regions of Zhuang People and maintained the internal political and economic structures of Zhuang ancestors. In this way, the politics, economy and culture of Zhuang People were greatly influenced, so as to maintain the government of people in border areas and promote the stability of the country. In this period, the slavery still prevailed in the west of Guilin and kept developing. The east of Guilin was under slavery in the early Tang period.

From the Tang Dynasty to the Five Dynasties, Zhuang ancestors commonly used iron tools and cattle farming, which not only promoted the further development of agriculture and but also promoted the development of handicraft industry in the regions of Zhuang people. In the Tang Dynasty, ancestors of Zhuang People made highquality textiles with local characteristics which were selected as tributes for governors. This shows that the textile technology of Zhuang people and corresponding clothing 
design and production and pattern design have been greatly developed and played an important role at that time.

\section{THE PERIOD DURING QIN AND HAN DYNASTIES AND FIVE DYNASTIES IS THE CONTENT OF BRONZE DRUM GRAPHIC DECORATION DESIGN OF THE ZHUANG PEOPLE}

In the period during Qin and Han dynasty and Five Dynasties, the Zhuang nationality uses typical implements decorative graphics in Central Plains for reference, at the same time, they create many design patterns full of local characteristics. Not only the implements such as Pankou Ting(an ancient cooking vessel), canister, bucket, sheep horn bell, table, cladode dagger, phoenix lights, dish, storehouse, coffin and bronze drum, etc. are in unique shapes and exquisite craft, but also the graphic designs on vessel shape also have distinctive national features.

The bronze drum graphic decoration design during this period can best embody the decorative graphic design features of Zhuang people and their ancestors. Lin Biao Lu Yi records: "One of the enjoyments of barbarians is bronze drum. Its shape is like waist drum and there is a head in one side. The diameter of the drum head is about 2 feet. And the head is connected with body and it casts with bronze. There are the shapes of insects, fish, flowers and grass on its body, the shape of which is even and the thickness is about 2 centimeters. The wonderful furnace casting is really ingenious." [3] People in Lingshan County excavate a bronze drum and there is coin plating printing "Kai Yuan Tong Bao" inside of the drum. Its skillful manufacture and a very high technological level indicate that the bronze casting industry in Zhuang minority region at that time has been quite developed. The graphic design on the surface of this drum is exquisite and delicate, and has careful and precise arrangement. Its graphic design decorative design mainly has graphic designs of people, animals and plants, geometric and ship form decorative patterns.

All in all, the graphic decoration design of bronze drum can be roughly divided into four groups:

1. Decorative pattern of people. The graphic design of people in bronze drum decorative pattern presents feathered people images with many local characteristics "Fig.1.". The graphic design of these feathered people divides into the shape of sculling on the boat, standing or dancing. The succinct lines portray the full-dress images of Zhuang ancestors. For example, the surface of the drum excavated in Shizhaishan depicts the scene that full-dress people dance together and there have ship lines of bronze drum on the side;

2. The decorative pattern of animals and plants as shown in "Fig.2" and "Fig. 3". These animal graphs appear on the bronze drum of Shizhaishan type, such as graphs of cormorant bird, fish and flying egret "Fig.4", egret with a fish in its mouth, monster, knight riding on a beast, birds and beasts and the face of beast, etc. These graphs describe the realistic characters and express people' $s$ fishing and hunting life style at that time. Depicting them on the bronze drum as the artifact actually is also the embodiment that the ancestors interact with the witchcraft beliefs.
3. The geometric decorative pattern. There are various forms of design such as grains of halo, clouds and thunder, water wave and square, etc. "Fig.5". What more distinctive is the swirl marks in the center of the bronze drum surface. The swirl marks are the main force bearing point when knocking the bronze drum. There are decorative lines grains and coherent copper cash grains around it. The rays of swirl marks divide into different types of 8 rays and 12 rays, which embody the concept that people worship the sun "Fig.6".

4. The decorative pattern of ship form. There are decorative patterns of feathered people on the boat, which is the most distinctive characteristic of bronze drum during this period. The shape of the boat is long and narrow and people on it are in single row and in line and we can only see one side of the people. There are many decorative patterns of bird head and feathers on the bow and stern, which is the portrayal that the Zhuang ancestors sail a boat on the water or carry through the "boat race". These graphs are exaggerated and abstract, embodying the Zhuang ancestors' superb abstract and modeling ability.

During Qin and Han dynasty, with the further development of ceramics in Zhuang minority region, the graphic design on pottery products receives further abundance. From the archaeological discoveries, the graphic design and production methods of pottery during this period have tooling mark, tap and print, pressure, addition, chasing, carving and colored drawing, etc. The specific graphic patterns are abundant and various. Only geometric decorative designs have 124 design patterns with different structures. [4] New graphical manifestation mode also appears during this period, which means putting colored drawing on the potteries. And the graphs often have grain of cirrus cloud, water wave and chord, etc.
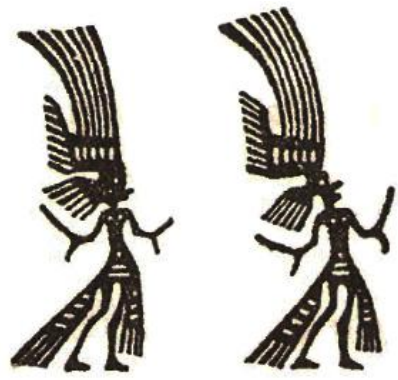

Fig. 1. Decorative graphic design on bronze drum- grain of feathered people

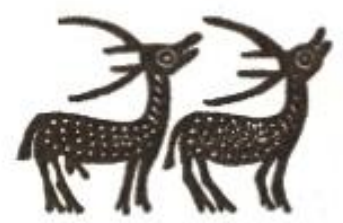

Fig. 2. Decorative graphic design on bronze drum- grain of animals 


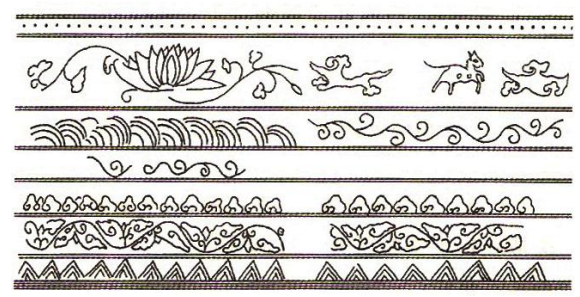

Fig. 3. Decorative graphic design on bronze drum- grain of plants

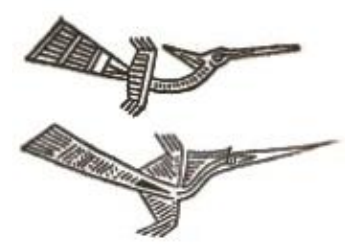

Fig. 4. Decorative graphic design on bronze drum-grain of flying egret

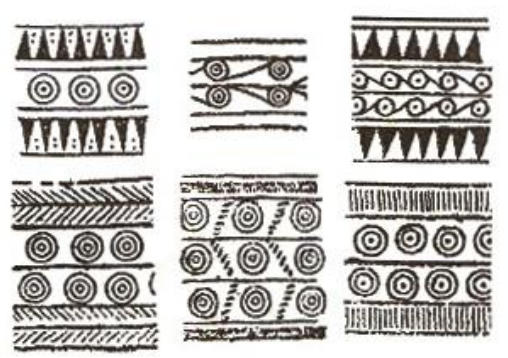

Fig. 5. Decorative graphic design on bronze drum- geometric decorative pattern

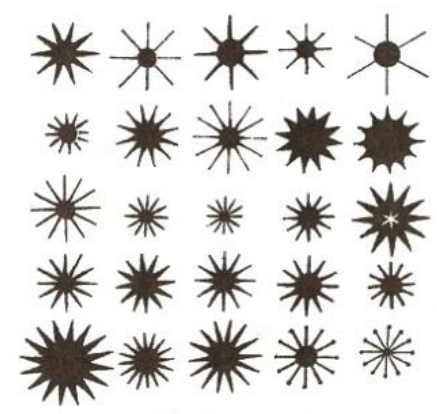

Fig. 6. Decorative graphic design on bronze drum- grain of sun rays of light

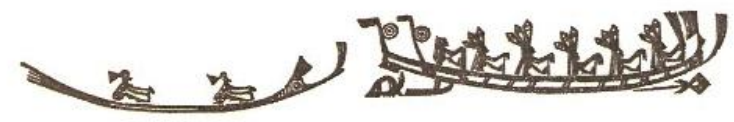

Fig. 7. Decorative graphic design on bronze drum- grain of boat
Protoporcelain of Zhuang region shaped between the Western Zhou Dynasty and the Warring States Period. Celadon came into being in the late Eastern Han Dynasty. The maturation and development of porcelain was between the Southern Dynasty and Sui Dynasty. There have been many historical relics found in Zhuang region, among them celadon is becoming more and more in number. Design of pictures on celadon wares is much more diversified. Celadon wares unearthed in a tomb of Southern Dynasty at Changchadi Gongcheng Street, Guangxi province were in many shapes, such as pot with dish-shaped mouth, dish, plate, bowl, three feet censer with a plate, ink stone with three feet, ware with three feet and so on. Among them there was a big plate with lotus figure on its center surrounded by a honeysuckle design. Besides, there was a small plate with fluffy flower design on its center. All the design of figures was based on nature, which indicated the atmosphere of life.

Design of figures on lacquer wares was very important since Qin and Han Dynasties. Many lacquer wares were unearthed from Luobowan Tomb 1 and Tomb 2 of Han dynasty in Gui County and Golden Bell Han dynasty tombs in He County. The shapes of these wares were ear cup, plate, table, incense container, box, bean, basin, bucket, mirror case, sword scabbard, knife scabbard, spear hilt, umbrella jacking and crutch. Most of these wares had figures on their surfaces. There were geometric figures, like wave and cirrus cloud, and animal figures like rhinoceros.

Lacquer painting on the bronze tubes and basins unearthed from Luobowan Tomb 1 of Han Dynasty was the representative of that time. Such as figures on Bamboo Bronze Tube. It could be found out according to its shape that it was a product by local people. [6] There were figures including people, animals, flowers, woods, and mountains painted by black paint. It was a Scroll Creative with a method of recording. There were four parts included. All figures in it such as people and animals were abstract and concise. What's more, there was a M1 : NO.1 Bronze Basin unearthed from this tomb as well. There were elegant lacquer painting figures on its mouth edge, surface and inside. Figures on its mouth edge were rhombic designs mainly. There were two dragons, fish and cirrus cloud figures. It seemed that two dragons were chasing each other. A carp was designed at the neck of a dragon and at the tail of another respectively. On its surface, there were four handle rings; four groups of designs which were for recording can be seen on these rings. Scholars pointed out that these figures formed a war-narrating picture. [7]

Bronze mirrors became common burial objects at Han Dynasty. Many bronze mirrors unearthed from Zhuang region were with delicate figures on their base, most of them were designed by local people in ancient times. There was one called Kui (a one-legged monster in fable) and Phoenix Bronze Mirror unearthed from Shendingling Tomb 1 of Eastern Han Dynasty at Gui County in 1965. It had a round base. There were four short wires stretched out from its base. The inner space was separated by it to four parts. There was a Kui or phoenix in each part, totally two Kui and two phoenixes. There were convex four-leaf figures on the silver cover, on which edge there were rhombic figures. In this case, 
someone predicted it was produced by local people in Guangxi province. [8]

Celadon industry in Zhuang region achieved great development during that period. Tombs of Tang Dynasty at Guangyang, Zhongshan, Guiping, Qinzhou all seen pots, loop-handled teapot vases, bowls and cups unearthed. They were elegant in their designs; their bodies and glaze were closely combined, which indicated high artistic level. [9]There was a VI-type bowl unearthed from tomb of Sui and Tang Dynasty at Qinzhou Guangxi province. In its center, we could see rose figures and other figures which were shaped by printing for several times. [10]

The bronze mirrors of Tang Dynasty unearthed from Zhuang region were mainly with eight-diagram figures and auspicious beasts' figures such as tigers and lions on them. Some of them were with inscription. There was a I -type bronze mirror unearthed from tomb of Sui and Tang Dynasty at Qinzhou Guangxi province. [11] On its edge, there was regular script inscription. The Zodiac animals figure was on it as well. Those all indicate high artistic level. There were also some representative bronze mirrors. For example, Lotus Bronze Mirror unearthed at Limu, Gongcheng County in 1976, Auspicious Beast Luan Feng Bronze Mirror unearthed at Gaode, Beihai County in 1972(Luan Feng is from a Chinese old saying, it represent husband and wife respectively) and Sea Animal Grape Square Bronze Mirror at Tengxian County in 1973. [12]

\section{THE CHARACTERISTICS OF THE ZHUANG DESIGN ART DURING THE PERIOD OF QIN AND HAN DYNASTY AND FIVE DYNASTIES}

In a word, the period during Qin and Han dynasty and Five Dynasties is the rudiment period of the Zhuang design art development. Through the learning and accumulation of technology in pre-Qin period, the decorative graphic design of the Zhuang ancestors fully combines local national culture and shows new characters:

- The types of decorative patterns obviously increase than the early stage. During this period, social production and social culture and economy obviously make progress. The implements of production that people use are more complicated than before and social division of labor is more obvious. The varieties of Zhuang design art are rich and colorful. The surfaces of many design works of art will attach delicate design patterns. Together with design works of art, these design patterns are the new start of design and art development for the later Zhuang people.

- It is the use of new technology that promotes the progress of the decorative graphic design. By this time, the progress of the iron smelting technology promotes the unprecedented prosperity of design art of bronze ware and the production technology of its decorative graphic design. Many fine bronze design products such as the bronze drum and copper phoenix light in Western Han and Eastern Han Dynasties all adopt chisel carved decorative pattern technology. When bronze ware design in the central plains region gradually declines, bronze ware design art in Zhuang minority region reaches the peak. At that time, many bronze appliances appearing in Zhuang minority region can match with the exquisite bronze ware excavated in central plains region. [13] During this period, the bronze design art in Zhuang minority region learns the technology in central plains as well as pay attention to the transformation of localization. Many bronze design art full of the characteristics of Zhuang minority region comes into being. For example, the design of copper phoenix light makes it can not only be used for lighting, but also prevent smoke and control dust, and keep out the wind and adjust the light. Besides, the decorative patterns on its surface are rich and colorful as well. For another example, ceramic firing technology also makes progress. Many unearthed pottery are more abundant than earlier stage on modeling and decorative patterns.

- The incoming cultural elements better mix together with local cultural elements, and combine with decorative graphic design art. Zhuang ancestors on one hand absorb the cultural elements of central plains region as well as other nationalities around them, integrate them into their own national culture and design many design works of art which have incoming cultural elements and cultural elements of their own nation. For example, man copper wares with chisel carved decorative pattern used by Zhuang ancestors are designed by people who absorb copper casting technology in central plains and integrate graphic design elements, customs and religious ideas, etc. of their own nation.

\section{REFERENCES}

[1] Qi Wanli. Discussion on Design Art of Zhuang People in the Pre-qin Period. Guangxi Social Science. 2013 (4).

[2] Zhang Shengzhen. History of Zhuang People. Beijing: Nationalities Publishing House. 1997: 307

[3] Liu Xun (Tang Dynasty). Lingbiaoluyi. Guangzhou: Guangdong People's Publishing House. 1983: 7.

[4] Zhang Shengzhen. History of Zhuang People. Beijing: Nationalities Publishing House. 1997: 366.

[5] Huang Qishan. Guangxi Tomb of Southern Dynasty in Xinjie Changcha of Gongcheng of Guangxi. Archaeology. 1983 (7).

[6] Archaeological Team of Guangxi Zhuang Autonomous Region. Brief Report of Luobowan No. 1 Tomb in Guixian County of Guangxi Province. Cultural Relics. 1978 (9).

[7] Jiang Tingyu. Analysis on Bronze Ware and Lacquer Painting Unearthed in Luobowan. Chinese Historical Relics. 2009 (4).

[8] Yu Fengzhi. Ancient Copper Mirrors Unearthed in Guangxi. Cultural Relics.1990 (1).

[9] Huang Qishan. Discussion on Blue Porcelains from the Eastern Han Dynasty to the Sui and Tang Dynasties Unearthed in Guangxi. Guangxi Cultural Relics. 1985 (2).

[10] Archaeological Team of Guangxi Zhuang Autonomous Region. Tombs of Sui Dynasty and Tang Dynasty in Qinzhou of Guangxi Zhuang Autonomous Region. Archaeology. 1984 (3). 
[11] Archaeological Team of Guangxi Zhuang Autonomous Region. Tombs of Sui Dynasty and Tang Dynasty in Qinzhou of Guangxi Zhuang Autonomous Region. Archaeology. 1984 (3).

[12] Zhang Shengzhen. History of Zhuang People. Beijing: Nationalities Publishing House. 1997: 548.

[13] Jiang Tingyu. Study on Bronze with Engraved Pattern of Han Dynasty. Journal of Archaeology. 2002 (3). 